\title{
PERAMALAN JUMLAH KENDARAAN DI DKI JAKARTA DENGAN JARINGAN BACKPROPAGATION
}

\author{
Alwi Smith ${ }^{1}$, Zumrotus Sya'diyah ${ }^{2}$ \\ ${ }^{1}$ Fakultas Keguruan dan Ilmu Pendidikan Universitas Pattimura \\ ${ }^{1}$ Fakultas Keguruan dan Ilmu Pendidikan Universitas Darussalam Ambon \\ Jl. Ir. M. Putuhena, Kampus Unpatti, Poka-Ambon, Indonesia \\ e-mail: ${ }^{1}$ alwi.smith1960@gmail.com, ${ }^{2}$ zuma.yakuza@gmail.com
}

\begin{abstract}
Abstrak
Kemacetan di ibukota DKI Jakarta tidak dapat dihindari, terutama pada titik-titik persimpangan baik di jalan-jalan protokol hingga di jalan lingkungan. Semakin hari, kemacetan di Jakarta semakin parah. Menurut sebuah penelitian, kemacetan tersebut membuat masyarakat Jakarta mengalami kerugian hingga Rp 48 triliun per tahun [1]. Dalam makalah ini akan dibahas mengenai prediksi jumlah kendaraan pada tahun 2017. Prediksi ini akan dilakukan dengan menggunakan jaringan syaraf tiruan, yaitu metode backpropagation. Metode ini digunakan karena keunggulannya dalam learning rate. Learning rate sangat berguna dalam menentukan prediksi dengan eror yang kecil. Prediksi jumlah kendaraan ini akan dilakukan pada kendaraan bermotor, mobil pribadi dan kendaraan umum. Sehingga dari hasil prdiksi ini akan dapat ditentukan langkah-langkah yang tepat untuk menekan laju pertumbuhan jumlah kendaraan. Dalam pembahasannya nanti akan digunakan Matlab 2009a.
\end{abstract}

Kata Kunci : jaringan syaraf tiruan, metode backpropagation..

\section{FORECASTING NUMBER OF VEHICLES IN DKI JAKARTA WITH BACKPROPAGATION NETWORK}

\begin{abstract}
Congestion in the capital city of Jakarta can not be spared, imagine at the intersection points both in the streets protocol up on the road environment. The more the day, the congestion in jakarta getting worse. According to a study, the congestion that caused the people of Jakarta to lose up to Rp 48 trillion per year [1]. In this paper will discuss about the prediction of the number of vehicles in 2017. This prediction will be done by using artificial neural network, the method of backpropagation. This method is used because of its superiority in learning. Level of learning is very useful in determining predictions with small errors. Predicted number of these vehicles will be done on motor vehicles, private cars and public transport. From the results of this preview will be determined the appropriate steps to suppress the growth rate of the number of vehicles. In the discussion will be used Matlab 2009a.
\end{abstract}

Keywords: artificial neural network, backpropagation method.

\section{Pendahuluan}

Kemacetan lalulintas Jakarta yang semakin akut ini membuat pemerintah Provinsi DKI Jakarta melakukan berbagai upaya untuk mengatasinya. Namun upaya ini seakan sia-sia jika melihat data terbaru jumlah kendaraan di Ibukota. Oleh karena itu, dibutuhkan prediksi yang akurat untuk mengetahui jumlah kendaraan tiap tahun agar dapat dilakukan tindakan preventif untuk menyesuaikan antara kebutuhan masyarakat atas kendaraan dengan kendaraan umum yang ada. Selain itu, dapat dilakukan juga pembatasan pada kepemilikan kendaraan. Hal ini diharapkan dapat membantu pemerintah dakam melakukan upaya penanganan terhadap kemacetan yang selalu terjadi dan bahkan bertambah parah tiap tahunnya. 
Dalam makalah ini akan dibahas mengenai prediksi jumlah kendaraan pada tahun 2017. Prediksi ini akan dilakukan dengan menggunakan jaringan syaraf tiruan, yaitu metode backpropagation. Metode ini digunakan karena keunggulannya dalam learning rate. Learning rate sangat berguna dalam menentukan prediksi dengan eror yang kecil. Prediksi jumlah kendaraan ini akan dilakukan pada kendaraan bermotor, mobil pribadi dan kendaraan umum. Sehingga dari hasil prdiksi ini akan dapat ditentukan langkah-langkah yang tepat untuk menekan laju pertumbuhan jumlah kendaraan. Dalam pembahasannya nanti akan digunakan Matlab 2009a.

\subsection{Jaringan Saraf Tiruan [2]}

Jaringan syaraf tiruan (artificial neural network) adalah pemrosesan sistem informasi pada karakteristik tertentu dalam keadan yang berhubungan dengan jaringan syaraf biologi. Jaringan syaraf tiruan dibangun berdasarkan generalisasi dari model matematika pada manusia atau syaraf biologi, didasarkan pada asumsi:

1) Pemrosesan informasi terjadi pada banyak element yang disebut neuron.

2) Sinyal berjalan diantara neuron yang terkoneksi jaringan.

3) Masing masing jaringan koneksi dihubungkan dengan bobot, yang mana didalam jaringan syaraf khusus, melipatgandakan transmisi sinyal.

4) Masing masing neuron mempergunakan fungsi aktifasi (biasanya nonlinier) ke jaringan inputnya untuk menentukan sinyal output.

Jaringan syaraf dikarakteristikkan oleh :

1) Polanya terkoneksi diantara neuron (disebut arsitektur)

2) Metode untuk menentukan bobot dari koneksi (disebut training atau learning, algoritma)

3) Fungsi aktifasi.

\subsection{Backpropagation [2]}

Backpropagation melatih jaringan untuk mendapatkan keseimbangan antara kemampuan jaringan untuk mengenali pola yang digunakan selama proses training serta kemampuan jaringan untuk memberikan respon yang benar terhadap pola inputan yang serupa (tapi tak sama) dengan pola yang dipakai selama training.

\subsubsection{Arsitektur}

Backpropagation memiliki beberapa unit yang ada di dalam satu atau lebih hidden layer.

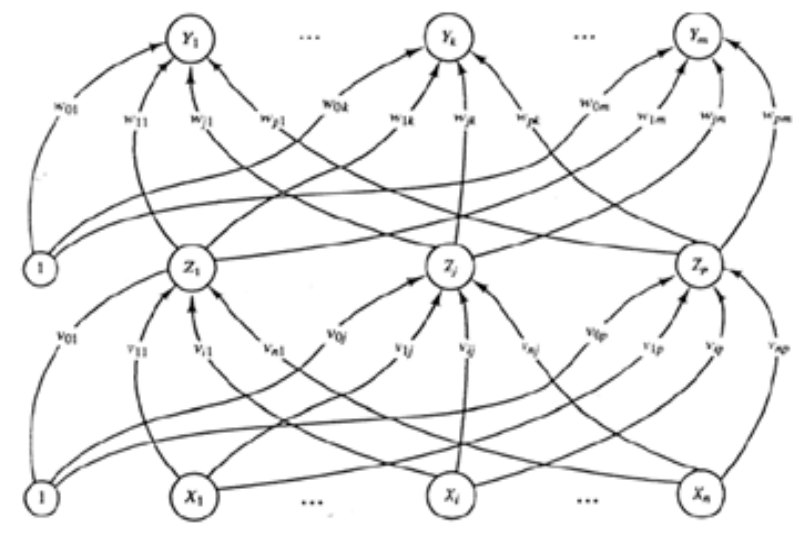

Gambar 1. Arsitektur backpropagation

Gambar 1 merupakan arsitektur backpropagation dengan $n$ buah inputan (ditambah sebuah bias), sebuah hidden layer yang terdiri dari $p$ unit (ditambah sebuah bias), serta $m$ buah unit output. Dimana $v_{i j}$ merupakan bobot garis dari unit input $x i$ ke unit hidden layer $z_{j}$ ( $v_{j 0}$ merupakan bobot garis yang menghubungkan bias di unit inputan ke unit hidden layerz $z_{j}$ ). $w_{j i}$ merupakan bobot dari unit hidden layer $z_{j}$ ke unit output $y_{k}$ ( $w_{k 0}$ merupakan bobot garis yang menghubungkan bias di unit hidden layer ke unit output $z_{k}$ ). 


\subsubsection{Fungsi Aktivasi}

Fungsi aktivasi untuk jaringan backpropagation memiliki beberapa karakteristik yang penting. Fungsi aktivasi tersebut kontinu, dapat diturunkan dan tidak turun secara monoton. Untuk efesiensi perhitungan, turunan dari fungsi aktivasi tersebut juga mudah dihitung. Fungsi aktivasi yang paling umum digunakan adalah nilai dari turunannya (pada nilai tertentu dari variabel independen) dapat diekspresikan dalam bentuk nilai dari fungsi aktivasi tersebut (pada nilai varibel independen).Fungsi aktivasi yang paling sering digunakan adalah fungsi sigmoid biner. Sedangkan fungsi lain yang juga cukup sering dipakai adalah fungsi sigmoid bipolar. Penjelasan dari kedua fungsi tersebut diberikn sebagai berikut:

1. Fungsi sigmoid biner untuk interval $(0,1)$

$$
\begin{aligned}
& f(x)=\frac{1}{1+e^{-x}} \\
& f^{\prime}(x)=f(x)\left(\left[1-f_{1}(x)\right]\right.
\end{aligned}
$$

2. Fungsi sigmoid bipolar dengan interval $(-1,1)$

$$
\begin{aligned}
& f(x)=\frac{2}{1+e^{-x}}-1 \\
& f^{\prime}(x)=\frac{1}{2}\left[1+f_{2}(x)\right]\left[1-f_{2}(x)\right]
\end{aligned}
$$

\subsubsection{Algoritma Backpropagation}

Step 0 : Inisialisasi bobot semua bobot dengan bilangan acak kecil

Bobot bias input $\left(v_{0_{j}}\right)=$ bilangan acak dari $-\beta$ dan $\beta$, dengan

Bobot input $\left(v_{i j}\right)=$ bilangan acak dari -0.5 dan 0.5

Bobot bias hidden $\left(w_{0 k}\right)$ dan bobot hidden $\left(w_{j k}\right)=$ bilangan acak dari -1 dan 1 .

Step 1 : Jika kondisi penghentian belum terpenuhi, lakukan Step 2-9

Step 2 : Untuk setiap pasang data pelatihan, lakukan langkah 3-8

Step 3 : Tiap unit input $\left(X_{i}, i=1, \ldots, \mathrm{n}\right)$ menerima sinyal dan meneruskannya ke unit hidden

Step 4 : Hitung semua output di unit hidden $(Z j, j=1, \ldots, \mathrm{p})$

$$
\begin{aligned}
& z_{-} i n_{j}=v_{0 j}+\sum_{i=1}^{n} x_{i} v_{i j} \\
& z_{j}=f\left(z_{-} i n_{j}\right)
\end{aligned}
$$

Step 5 : Hitung semua output di unit output $(Y k, k=1, . ., \mathrm{m})$

$$
\begin{aligned}
& y_{-} i n_{k}=w_{0 k}+\sum_{j=1}^{p} z_{j} w_{j k} \\
& y_{k}=f\left(y_{-} i n_{k}\right)
\end{aligned}
$$

Step 6 : Hitung $\delta$ unit output berdasarkan error di setiap unit output $Y_{k}$

$$
\delta_{k}=\left(t_{k}-y_{k}\right) f^{\prime}\left(y_{-} i n_{k}\right)
$$

Hitung suku perubahan bobot hidden dan bobot bias hidden dengan learning ratea

$$
\begin{aligned}
& \Delta w_{j k}=\alpha \delta_{k} z_{j} \\
& \Delta w_{0 k}=\alpha \delta_{k}
\end{aligned}
$$


Step 7 : Hitung $\delta$ unit hidden berdasarkan error di setiap unit hidden $Z j$

Hitung suku perubahan bobot input dan bobot bias input dengan learning rate $\alpha$

$$
\begin{aligned}
& \delta_{-} i n_{j}=\sum_{k=1}^{m} \delta_{k} w_{j k} \\
& \delta_{j}=\delta_{-} i n_{j} f^{\prime}\left(z_{-} i n_{j}\right) \\
& \Delta v_{i j}=\alpha \delta_{j} x_{i} \\
& \Delta v_{0 j}=\alpha \delta_{j}
\end{aligned}
$$

Step 8 : Hitung semua perubahan bobot

$$
\begin{aligned}
& w_{j k}(\text { baru })=w_{j k}(\text { lama })+\Delta w_{j k} \\
& v_{i j}(\text { baru })=v_{i j}(\text { lama })+\Delta v_{i j}
\end{aligned}
$$

Step 9 : Test kondisi penghentian

\section{Hasil dan Pembahasan}

\subsection{Analisa Data}

Sebagaimana telah disebutkan sebelumnya bahwa data yang akan digunakan dalam proses peramalan atau prediksi ini adalah data jumlah kendaraan di Jakarta selama sepuluh tahun terakhir. Data ini akan digunakan untuk mengetahui kisaran yang akurat tentang jumlah kendaraan Data yang digunakan dalam proses prediksi adalah sebagai berikut:

Tabel 1. Data Jumlah Kendaraan Polda Metro Jaya [3]

\begin{tabular}{|c|c|c|c|c|c|}
\hline \multirow{2}{*}{ Tahun } & \multicolumn{4}{|c|}{ Jenis Kendaraan Bermotor } & \multirow{2}{*}{ Jumlah } \\
\cline { 2 - 5 } & Sepeda Motor & $\begin{array}{c}\text { Mobil } \\
\text { Penumpang }\end{array}$ & Mobil Beban & $\begin{array}{c}\text { Mobil Bis } \\
\text { Penumpang }\end{array}$ & \\
\hline 2007 & 1.813 .136 & 1.130 .496 & 347.443 & 253.648 & 3.544 .723 \\
\hline 2008 & 2.257 .194 & 1.195 .871 & 366.221 & 254.849 & 4.074 .135 \\
\hline 2009 & 3.316 .900 & 1.529 .824 & 464.748 & 315.652 & 5.627 .124 \\
\hline 2010 & 3.940 .700 & 1.645 .306 & 488.517 & 316.396 & 6.390 .919 \\
\hline 2011 & 4.647 .435 & 1.766 .801 & 499.581 & 316.502 & 7.230 .319 \\
\hline 2012 & 5.310 .068 & 1.835 .653 & 504.727 & 317.050 & 7.967 .498 \\
\hline 2013 & 5.947 .173 & 1.916 .469 & 518.991 & 318.332 & 8.727 .965 \\
\hline 2014 & 6.765 .723 & 2.034 .943 & 538.731 & 308.528 & 9.647 .925 \\
\hline 2015 & 7.084 .753 & 2.054 .254 & 507.410 & 308.941 & 9.955 .358 \\
\hline 2016 & 8.484 .384 & 2.285 .802 & 564.776 & 322.440 & 11.657 .402 \\
\hline
\end{tabular}

(Sumber: www.komisikepolisianindonesia.com, 2016)

Tampak pada tabel bahwa kenaikan jumlah kendaraan di Jakarta sangat signifikan. Tapi, tiap tahun mempunyai tingkat kenaikan yang berbeda-berbeda. Hal inilah yang membuat prediksi atas data selanjutnya yang akurat menjadi sulit didapatkan. Oleh karena itu, akan digunakan metode backpropagation untuk meramalkan data berikutnya. Program akan blajar untuk mengetahui model kenaikan jumlah kendaraan yang berubah dan berbeda tiap tahunnya.

\subsection{Hasil dan Representasi Prediksi}

Pada metode backpropagation, langkah yang pertama dilakukan adalah menentukan bobot awal. Pemilihan bobot awal akan mempengaruhi apakah jaringan mencapai minimum global (atau hanya lokal) dari error, dan jika itu terjadi, seberapa cepat akan konvergen. Update bobot antara dua unit bergantung pada turunan fungsi aktivasi dari unit batas atas dan unit batas bawah. Untuk alasan inilah, sangat penting untuk menghindari pemilihan bobot awal yang akan membuat aktivasi atau turunan dari aktivasi tersebut bernilai nol. Nilai dari bobot awal tidak harus terlalu besar, atau sinyal input awal ke tiap unit hidden atau output akan jatuh pada daerah dimana turunan dari fungsi sigmoid memiliki nilai yang sangat kecil (disebut area saturation). Selain itu, apabila bobot awal terlalu kecil, input jaringan untuk unit hidden atau output akan mendekati nol, yang akan menyebabkan proses learning yang sangat lambat. 
Prosedur umum adalah untuk memberi bobot awal (dan bias) dengan nilai acak antara -0.5 dan 0.5 (atau antara -1 dan 1 atau interval lain yang sesuai). Nilai tersebut bisa negatif maupun positif karena nilai akhir dari bobot setelah training mungkin sesuai dengan tanda tersebut.

Pada metode ini, proses training tidak dilakukan pada seluruh data, melainkan hanya sebagian saja (biasanya setengah dari data keseluruhan). Sedangkan sisa data yang lain digunakan dalam proses testing. Dalam training, bobot akan diperbarui di setiap iterasi sedemikian hingga diperoleh bobot yang sesuai dengan model data. Sedangkan proses testing akan menentukan seberapa akurat prediksi yang telah dilakukan. Hal inilah yang membuat metode ini unggul dari metode yang lain.

Bobot input yang dipakai adalah data yang bernilai $(-0.5,0.5)$. Bobot ini akan diinputkan ke program dalam bentuk matriks yang ukurannya sesuai dengan jumlah data yang akan diproses dan jumlah hidden layer yang diinginkan. Untuk jaringan syaraf tiruan dengan lebih dari 1 unit hidden, hanya modifikasi kecil dari algoritma backpropagation pada bab 2.2.2. Perhitungan dari $\delta$ diulang untuk setiap hidden layer. Hasil teoritis yang telah banyak ditunjukkan pada mennyimpulkan bahwa satu hidden layer cukup bagi sebuah jaringan backpropagation untuk menetapkan setiap pemetaan kontinu dari pola input ke pola output pada sebarang derajat ketepatan. Bagaimanapun juga, 2 hiden layer mungkin dapat membuat training lebih mudah untuk beberapa situasi. Sedangkan bobot awal untuk bobot input diambil nilai $[-\beta, \beta]$, dengan $\beta=0.7(p)^{1 / n}=0.7 \sqrt[n]{p}$. Dan bobot awal untuk bobot hidden diambil nilai $(-0.5,0.5)$.

Dari penjelasan tersebut, maka dalam makalah ini akan digunakan bobot input data yang bernilai $(0.5,0.5)$, jumlah data adalah 10 dan banyak hiden layer adalah 1 . Oleh karena itu, dapat diambil suatu inisialisasi bobot berupa matriks berukuran $5 \times 1$ yang dinyatakan dalam tabel berikut:

Tabel 2. Bobot Input

\begin{tabular}{|c|}
\hline Bobot input \\
\hline 0.2 \\
\hline 0.2 \\
\hline 0.2 \\
\hline 0.2 \\
\hline 0.2 \\
\hline
\end{tabular}

Karena data yang dimiliki bernilai sangat besar, maka perlu dilakukan konversi dengan rumus berikut:

$$
x_{-} \text {baru }=\frac{x_{-} \text {lama }-x_{-} \min }{x_{-} \text {maks }-x_{-} \min }
$$

Konversi ini pada akhir peramalan atau prediksi akan dikembalikan lagi dengan invers dari persamaan tersebut sebagai berikut:

$$
y_{-} \text {pred }=y_{-} l a m a *\left(y_{-} \text {maks }-y_{-} \min \right)+y_{-} \min
$$

Sehingga, konversi ini tidak akan mengubah data yang dihasilkan. Dari proses konversi pada data input diperoleh:

Tabel 3. Hasil Konversi data Inputan

\begin{tabular}{|r|r|r|r|r|r|}
\hline \multirow{2}{*}{ Tahun } & \multicolumn{4}{|c|}{ Jenis Kendaraan Bermotor } & \multirow{2}{*}{ Jumlah } \\
\cline { 2 - 5 } & Sepeda Motor & Mobil Penumpang & \multicolumn{1}{l}{ Mobil Beban } & \multicolumn{1}{l|}{ Mobil Bis } & 0 \\
\hline 2007 & 0 & 0 & 0 & 0 & 0.065257 \\
\hline 2008 & 0.066563 & 0.056587 & 0.086402 & 0.017458 & 0.256685 \\
\hline 2009 & 0.22541 & 0.345647 & 0.539748 & 0.901326 & 0.350833 \\
\hline 2010 & 0.318915 & 0.445605 & 0.649114 & 0.912141 & 0.454301 \\
\hline 2011 & 0.424853 & 0.550768 & 0.700023 & 0.913682 & 0.545168 \\
\hline 2012 & 0.52418 & 0.610364 & 0.7237 & 0.921648 & 0.638906 \\
\hline 2013 & 0.61968 & 0.680316 & 0.789332 & 0.940284 & 0.752304 \\
\hline 2014 & 0.742378 & 0.782864 & 0.880161 & 0.797767 & 0.7902 \\
\hline 2015 & 0.7902 & 0.799579 & 0.723765 & 0.803771 & 1 \\
\hline 2016 & 1 & 1 & 1 & 1 & 1 \\
\hline
\end{tabular}

Data pada Tabel 3 adalah data inputan untuk program. Setelah running, yaitu dengan jumlah hidden layer adalah 1, learning rate sebesar 0.5, banyak iterasi adalah 3 (telah mencapai kekonvergenan, artinya bobot tidak terbarui lagi), bobot bias input adalah 0.7 , bobot bias hidden adalah 0.5 , dan bobot hidden layer 
(berukuran 1x1) sebesar 0.2, diperoleh data hasil running program sebagaimana dijelaskan dalam sub bab berikut ini.

\subsubsection{Prediksi Jumlah Kendaraan Bermotor}

Setelah dilakukan running program terhadap data jumlah kendaraan bermotor selama sepuluh tahun terakhir, diperoleh data-data sebagai berikut:

Tabel 4. Bobot Awal dan Akhir layer

\begin{tabular}{|c|c|}
\hline Bobot Awal Input & Bobot akhir Input $\left(\times 10^{5}\right)$ \\
\hline 0.7 & 1.0879 \\
\hline 0.2 & 0.0000 \\
\hline 0.2 & 0.0724 \\
\hline 0.2 & 0.2452 \\
\hline 0.2 & 0.3470 \\
\hline 0.2 & 0.4622 \\
\hline
\end{tabular}

a) Bobot Awal dan Akhir layer input

\begin{tabular}{|c|c|}
\hline Bobot Awal Hidden & Bobot Akhir Hidden $\left(\times 10^{7}\right)$ \\
\hline 0.5 & 5.0388 \\
\hline 0.2 & 4.9625 \\
\hline
\end{tabular}

b) Bobot Awal dan Akhir hidden layer

Sehingga diperoleh data prediksi jumlah kendaraan bermotor pada tahun 2017 adalah sebesar $8.6895 \times 10^{6}$. Hal ini digambarkan dengan garis merah pada grafik berikut:

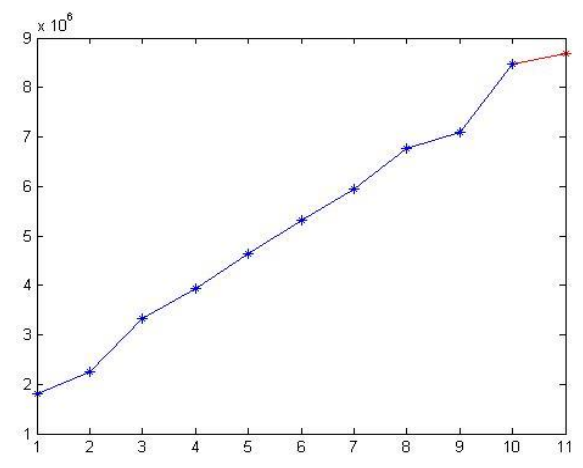

Grafik 1. Hasil Prediksi Jumlah Kendaraan Bermotor

\subsubsection{Prediksi Jumlah Mobil Penumpang}

Setelah dilakukan running program terhadap data jumlah mobil penumpang selama sepuluh tahun terakhir, diperoleh data-data sebagai berikut:

Tabel 5. Bobot Awal dan Akhir layer

\begin{tabular}{|c|c|}
\hline Bobot Awal Input & Bobot akhir Input $\left(\times 10^{4}\right)$ \\
\hline 0.7 & 3.6429 \\
\hline 0.2 & 0.0000 \\
\hline 0.2 & 0.2062 \\
\hline 0.2 & 1.2591 \\
\hline 0.2 & 1.6233 \\
\hline 0.2 & 2.0064 \\
\hline
\end{tabular}

a) Bobot Awal dan Akhir layer input

\begin{tabular}{|c|c|}
\hline Bobot Awal Hidden & Bobot Akhir Hidden $\left(\times 10^{7}\right)$ \\
\hline 0.5 & 1.5191 \\
\hline 0.2 & 1.4940 \\
\hline
\end{tabular}

b) Bobot Awal dan Akhir hidden layer 
Sehingga diperoleh data prediksi jumlah mobil penumpang pada tahun 2017 adalah sebesar $2.3665 \times 10^{6}$. Hal ini digambarkan dengan garis merah pada grafik berikut:

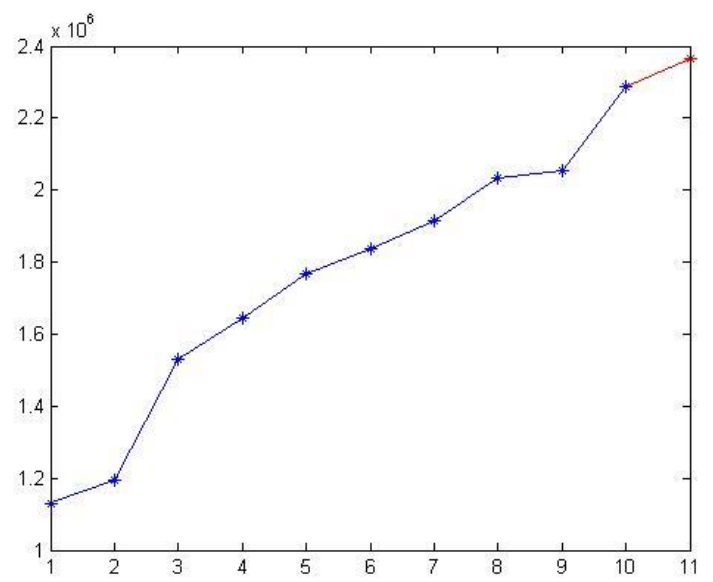

Grafik 2. Hasil Prediksi Jumlah Mobil Penumpang

\subsubsection{Prediksi Jumlah Mobil Beban}

Setelah dilakukan running program terhadap data jumlah mobil beban selama sepuluh tahun terakhir, diperoleh data-data sebagai berikut:

Tabel 6. Bobot Awal dan Akhir layer

\begin{tabular}{|c|c|}
\hline Bobot Awal Input & Bobot akhir Input $\left(\times 10^{3}\right)$ \\
\hline 0.7 & 9.4811 \\
\hline 0.2 & 0.0002 \\
\hline 0.2 & 0.8193 \\
\hline 0.2 & 5.1172 \\
\hline 0.2 & 6.1541 \\
\hline 0.2 & 6.6367 \\
\hline
\end{tabular}

a) Bobot Awal dan Akhir layer input

\begin{tabular}{|c|c|}
\hline Bobot Awal Hidden & Bobot Akhir Hidden $\left(\times 10^{6}\right)$ \\
\hline 0.5 & 3.9479 \\
\hline 0.2 & 3.8847 \\
\hline
\end{tabular}

b) Bobot Awal dan Akhir hidden layer

Sehingga diperoleh data prediksi jumlah mobil beban pada tahun 2017 adalah sebesar $5.9050 \times 10^{5}$. Hal ini digambarkan dengan garis merah pada grafik berikut:

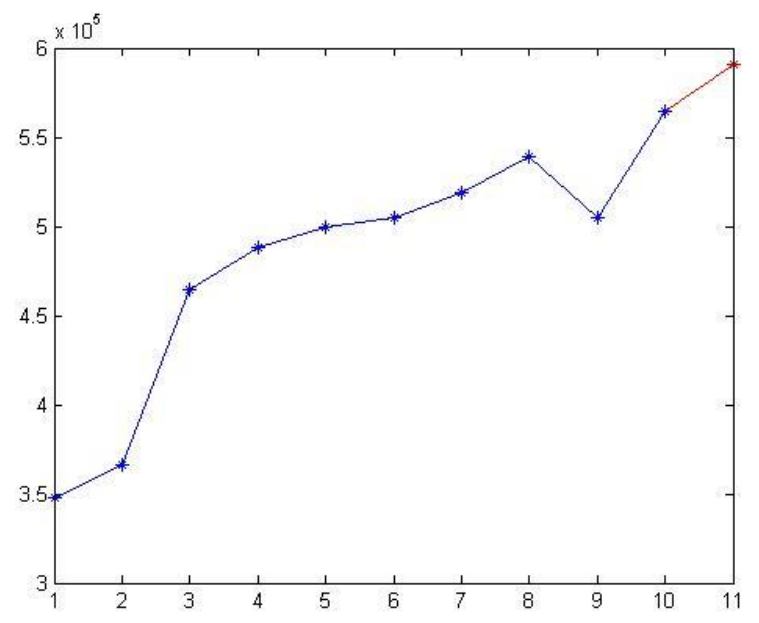

Grafik 3. Hasil Prediksi Jumlah Mobil Beban 


\subsubsection{Prediksi Jumlah Mobil B is}

Setelah dilakukan running program terhadap data jumlah mobil bis selama sepuluh tahun terakhir, diperoleh data-data sebagai berikut:

Tabel 7. Bobot Awal dan Akhir layer

\begin{tabular}{|c|c|}
\hline Bobot Awal Input & Bobot akhir Input $\left(\times 10^{3}\right)$ \\
\hline 0.7 & 5.4923 \\
\hline 0.2 & 0.0002 \\
\hline 0.2 & 0.0961 \\
\hline 0.2 & 4.9499 \\
\hline 0.2 & 5.0093 \\
\hline 0.2 & 5.0177 \\
\hline
\end{tabular}

a) Bobot Awal dan Akhir layer input

\begin{tabular}{|c|c|}
\hline Bobot Awal Hidden & Bobot Akhir Hidden $\left(\times 10^{6}\right)$ \\
\hline 0.5 & 2.3629 \\
\hline 0.2 & 2.3276 \\
\hline
\end{tabular}

b) Bobot Awal dan Akhir hiddenlayer

Sehingga diperoleh data prediksi jumlah mobil beban pada tahun 2017 adalah sebesar $3.4102 \times 10^{5}$. Hal ini digambarkan dengan garis merah pada grafik berikut:

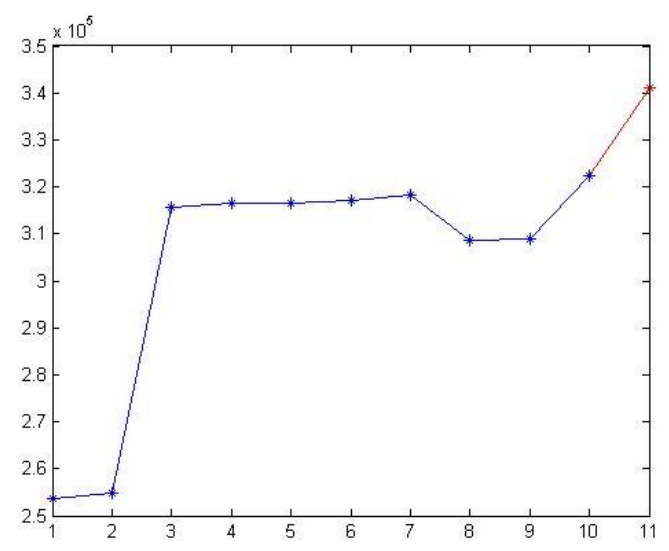

Grafik 4. Hasil Prediksi Jumlah Mobil Bis

\subsubsection{Prediksi Jumlah Total Seluruh Kendaraan}

Setelah dilakukan running program terhadap data jumlah total seluruh kendaraan selama sepuluh tahun terakhir, diperoleh data-data sebagai berikut:

Tabel 8. Prediksi jumlah Total kendaraan tahun 2017

\begin{tabular}{|c|r|}
\hline & $\begin{array}{c}\text { Prediksi kenaikan jumlah tiap } \\
\text { jenis kendaraan }\end{array}$ \\
\hline Sepeda Motor & 8.689 .500 \\
\hline Mobil Penumpang & 2.366 .500 \\
\hline Mobil Beban & 590.500 \\
\hline Mobil Bis & 341.020 \\
\hline Jumlah Total & 11.987 .520 \\
\hline
\end{tabular}

Sehingga diperoleh data prediksi jumlah total seluruh kendaraan pada tahun 2017 adalah sebesar 11.987.520. Hal ini digambarkan dengan garis merah pada grafik berikut: 


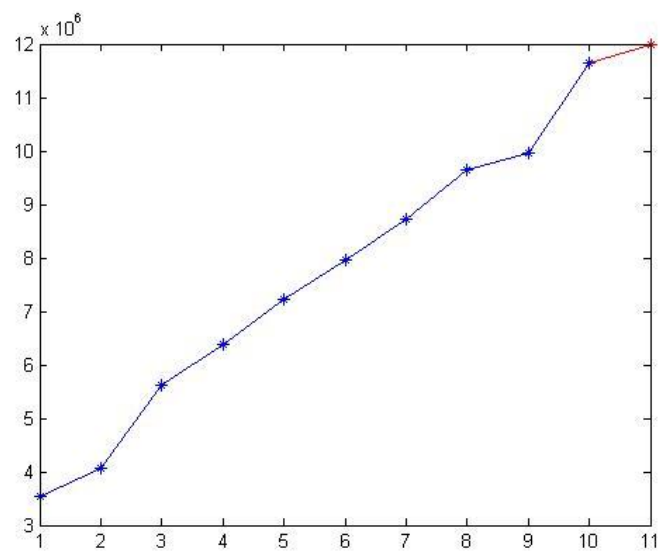

Grafik 5. Hasil Prediksi Jumlah Total Kendaraan

\section{Kesimpulan} berikut:

Dari penggunaan program menggunakan metode backpropagation, diperoleh hasil prediksi sebagai

\begin{tabular}{|c|r|}
\hline & $\begin{array}{c}\text { Prediksi kenaikan jumlah tiap jenis } \\
\text { kendaraan }\end{array}$ \\
\hline Sepeda Motor & 8.689 .500 \\
\hline Mobil Penumpang & 2.366 .500 \\
\hline Mobil Beban & 590.500 \\
\hline Mobil Bis & 341.020 \\
\hline Jumlah Total & 11.987 .520 \\
\hline
\end{tabular}

Tabel menunjukkan bahwa jumlah sepeda motor naik sebanyak 205.116 unit dari data september 2016, mobil penumpang naik 80.698 unit, mobil beban naik sebanyak 25.724 unit, mobil bis naik 18.580 unit, sedangkan total jumlah kendaraan akan mangalami kenaikan pula sebesar 330.118 unit.

Kenaikan ini harus diatasi dengan pengurangan jumlah kendaraan. Hal ini dapat dilakukan dengan mengadakan uji kelayakan kendaraan dimana kendaraan yang sudah tak layak operasi harus segera diberhentikan ijin beroperasinya. Selain itu, pengurangan tingkat kenaikan jumlah kendaraan dapat dilakukan juga dengan mengurangi pembelian kendaraan dengan cara kredit. Hal ini dikarenakan oleh pemberian kredit dengan bunga yang terlalu rendah meningkatkan keinginan dan daya beli masyarakat atas kendaraan bermotor. Dan kasus ini menyumbangkan pengaruh besar bagi meroketnya jumlah kendaraan. Cara lain yang juga dapat dilakukan adalah membatasi kepemilikan kendaraan bagi tiap keluarga. Hal ini disebabkan oleh tingginya tingkat konsumsi masyarakat Indonesia atas barang mewah, terutama mobil.

\section{Daftar Pustaka}

1. Fausett, Laurence. Fundamentals of Neural Network: Architectures, Fundamentals, and Applications. Newe Jersey: Prentice-Hall, Inc., 1994.

2. Susanto. www.Detik News.com. [Online] 26 November 2008. [Dikutip: 23 Juni 2015.] www.Detik News.com//kemacetan_susanto_26NOV2008.

3. Kompolnas. www.komisikepolisianindonesia.com. [Online] Juni 2016. www.komisikepolisianindonesia.com/data_kendaraan_2016. 